\title{
Explaining European fungal fruiting phenology with climate variability
}

\author{
Carrie Andrew, ${ }^{1,2,3,14}$ Einar Heegaard, ${ }^{4}$ Klaus Høiland, ${ }^{3}$ Beatrice Senn-Irlet, ${ }^{1}$ Thomas W. Kuyper, ${ }^{5}$ Irmgard \\ Krisai-Greilhuber, ${ }^{6}$ Paul M. Kirk, ${ }^{7}$ Jacob Heilmann-Clausen,${ }^{8}$ Alan C. Gange, ${ }^{9}$ Simon Egli, ${ }^{1}$ Claus Bässler,${ }^{10,11}$ \\ Ulf Büntgen, ${ }^{1,2,12}$ Lynne Boddy, ${ }^{13}$ and Håvard Kauserud ${ }^{3}$ \\ ${ }^{1}$ Swiss Federal Research Institute WSL, CH-8903 Birmensdorf, Switzerland \\ ${ }^{2}$ Department of Geography, University of Cambridge, Cambridge CB2 3EN United Kingdom \\ ${ }^{3}$ Section for Genetics and Evolutionary Biology (EVOGENE), University of Oslo, Blindernveien 31, 0316 Oslo, Norway \\ ${ }^{4}$ Forestry and Forest Resources, Norwegian Institute of Bioeconomy Research, Fanaflaten 4, N-5244 Fana, Norway \\ ${ }^{5}$ Department of Soil Quality, Wageningen University, PO Box 47, 6700 AA Wageningen, The Netherlands \\ ${ }^{6}$ Department of Botany and Biodiversity Research, University of Vienna, A-1030 Vienna, Austria \\ ${ }^{7}$ Mycology Section, Jodrell Laboratory, Royal Botanic Garden, Kew, Surrey TW9 3DS United Kingdom \\ ${ }^{8}$ Centre for Macroecology, Evolution and Climate, Natural History Museum of Denmark, University of Copenhagen, \\ DK-2100 Copenhagen, Denmark \\ ${ }^{9}$ School of Biological Sciences, Royal Holloway, University of London, Egham, Surrey TW20 OEX United Kingdom \\ ${ }^{10}$ Bavarian Forest National Park, Freyunger Street 2, D-94481 Grafenau, Germany \\ ${ }^{11}$ Chair for Terrestrial Ecology, Technical University of Munich, Hans-Carl-von-Carlowitz-Platz 2, 85354 Freising, Germany \\ ${ }^{12}$ Global Change Research Centre, Masaryk University, 61300 Brno, Czech Republic \\ ${ }^{13}$ School of Biosciences, Cardiff University, Sir Martin Evans Building, Museum Avenue, Cardiff CF10 3 AX United Kingdom
}

Abstract. Here we assess the impact of geographically dependent (latitude, longitude, and altitude) changes in bioclimatic (temperature, precipitation, and primary productivity) variability on fungal fruiting phenology across Europe. Two main nutritional guilds of fungi, saprotrophic and ectomycorrhizal, were further separated into spring and autumn fruiters. We used a path analysis to investigate how biogeographic patterns in fungal fruiting phenology coincided with seasonal changes in climate and primary production. Across central to northern Europe, mean fruiting varied by approximately $25 \mathrm{~d}$, primarily with latitude. Altitude affected fruiting by up to $30 \mathrm{~d}$, with spring delays and autumnal accelerations. Fruiting was as much explained by the effects of bioclimatic variability as by their large-scale spatial patterns. Temperature drove fruiting of autumnal ectomycorrhizal and saprotrophic groups as well as spring saprotrophic groups, while primary production and precipitation were major drivers for spring-fruiting ectomycorrhizal fungi. Species-specific phenology predictors were not stable, instead deviating from the overall mean. There is significant likelihood that further climatic change, especially in temperature, will impact fungal phenology patterns at large spatial scales. The ecological implications are diverse, potentially affecting food webs (asynchrony), nutrient cycling and the timing of nutrient availability in ecosystems.

Key words: climate; distribution; Europe; fruit bodies; fungi; NDVI; nutritional mode; path analysis; phenology.

\section{INTRODUCTION}

Research questions in biogeography often address the distribution and biodiversity of organisms across different spatiotemporal scales. Mycological examples include latitudinal gradients of richness estimates (Tedersoo et al. 2014, Davison et al. 2015), beta diversities between disjunct sampling points (Glassman et al. 2015), and geographical linkages of fungal nutritional modes with vegetation groups (Swaty et al. 2016, Bueno et al. 2017). Moreover, it is important to understand phenological patterns at large spatial scales, especially as they signify the timing of key events related to reproduction and dispersal (Kauserud et al. 2008, 2011, Peay et al. 2012). Earlier studies concerning the effects of climate and temporal change on phenology were limited in space and time (Gange et al. 2007, Kauserud et al. 2008, 2010, 2012, Büntgen et al. 2012, Boddy et al. 2014). However, it is important to assess much broader-scale biogeographic patterns in fungal phenology over statistically

Manuscript received 12 November 2017; revised 17 January 2018; accepted 21 February 2018. Corresponding Editor: Matthias C. Rillig.

${ }^{14}$ E-mail: carrie.j.andrew@gmail.com meaningful periods. This has never been done before at the continental scale, because the necessary data have only just become available (Andrew et al. 2017).

Within this context, there are numerous questions that have been well examined for plants, and which would be sensible to consider for fungi. For example, early vs. late season plant susceptibility to phenology responses (Gallinat et al. 2015, Parmesan and Hanley 2015, Xie et al. 2015) could affect the intra-annual timing of fungal fruiting via photosynthetic and litter dynamics coupled to nutrient cycling and ecological mismatch. Early-season plant species are often considered more attuned to abiotic conditions, and thus more sensitive to climatic changes, than are mid- to late-season species (Pau et al. 2011). However, as originally fewer studies were related to autumnal phenology, it might actually be a very responsive season for various species (Parmesan and Hanley 2015). Autumnal responses would include fruit ripening, nutrient and carbon resorption (decay or transfer) and storage belowground, and leaf senescence all features highly important to or with an equivalent component in fungal ecology.

Fungi exhibit a high diversity in their feeding preferences (nutritional modes; fungal guild) than organisms in most 
other kingdoms. Two major groups are saprotrophic (decomposing dead organic matter) and mycorrhizal (symbiotically associated with living plants, exchanging nutrients for carbon). Ecological patterns often separate out in accordance with these groupings (e.g., Soudzilovskaia et al. 2015, Bueno et al. 2017). At regional scales, saprotrophic fungi fruit earlier in spring and fruiting extends later in autumn than for ectomycorrhizal fungi (Kauserud et al. 2012, Andrew et al. 2018). This is probably related more to seasonal end and its effects on resource availability for ectomycorrhizal than saprotrophic fungi. The latter demonstrate a large phenological direct response to climate signals while that of ectomycorrhizal fungi is likely to be more directly related to variability in primary production (Kauserud et al. 2012, Andrew et al. 2018), itself related to climate.

While climate is accepted as a main contributor to phenological change, in many organisms its effect is dependent upon biotic and geographical (spatial) conditions. These connections between climatic, biotic, and geographical variabilities have not been clearly determined for fungal phenology at continental scales. Given substantial impacts to other biological organisms (Stenseth et al. 2002, Pau et al. 2011, Austen et al. 2017), we can expect fungal phenology to be patterned by biogeographical dependencies of climate and seasonality. Here we investigated climate impacts and the interdependencies (interrelatedness) between geography, altitude, and primary production on fungal biogeographical patterning. We also assessed how differing phenology responses were across species and related to seasonality and ecology (Diez et al. 2013).

It is generally assumed that biogeographic patterns of fungi reflect seasonal variation across the European continent; fungi fruit later where spring onset is later, and fruit longer into the year where autumnal onset is either later or more prolonged (Kauserud et al. 2010). However, the extent to which bioclimatic and geographical variance might influence phenology patterns at such a large spatial scale, and between the groups of fungi that fruit in different seasons and different nutritional modes, remains unclear. Our aim was to quantify the extent to which climate influences phenological trends in fungal fruiting, as well as the relation between the bioclimatic variables themselves. We assessed whether bioclimatic and geographic patterns could be explained outside the context of one another, and to what extent the latter could explain the former. Climate-related effects were hypothesized to greater impact autumn-fruiting and saprotrophic fungi, while the influence of primary productivity was expected to be greater for ectomycorrhizal fungi. Finally, we explored how contemporary to future changes in temperature, precipitation and primary productivity might influence, further, fungal fruiting phenology shifts. These objectives render this study unique compared to earlier fungal phenology research, including studies utilizing selections from the same data (see references above): the analyses directly incorporate climate variables (i.e., temperature and precipitation) into the models, instead of inferring climate impacts from temporal change; both the direct and indirect impacts of climate are assessed, and in combination with geographical effects on fruiting phenology as well as primary productivity; finally, the most geographically extensive data coverage, to this date, is utilized (covering as much of Europe as currently possible).

\section{Methods}

\section{Data sources, processing and bias removals}

The over 6 million records of fungal fruiting observations utilized for this study originated from multiple sources (museums, herbaria, societies, and citizen science projects) across eight European countries (Austria, Denmark, Germany, the Netherlands, Norway, Slovenia, Switzerland, and the United Kingdom). The data were previously assembled and formatted into one main meta-database, and included initial bias-removal processing (Andrew et al. 2017), for example, removing duplicate records, geographical outliers, records without complete dates, and harmonizing nomenclature. While further biases and skewness in this form of data have been earlier discussed (e.g., Halme et al. 2012, Boddy et al. 2014, Davis et al. 2015; for example, potential for collector biases), phenological responses have also been found to be robust across these types of data, and across spatial scales as well as sources, when appropriately analyzed and especially when a combination of multi-source data are used, as in the present study (Andrew et al. 2018).

To increase robustness further, the taxonomy and temporal distributions of the fungal records were additionally limited. Data were aggregated by geographical unit and species across the years 1970-2010, corresponding to the decades with the most data coverage (Andrew et al. 2017). Almost 4 million records were extracted for the majority of orders forming (more or less) macroscopic, ephemeral, fruit bodies of the Basidiomycota and Ascomycota, i.e., the Agaricales, Boletales, Cantharellales, Pezizales, and Russulales (Appendix S1: Fig. S1). While efforts to delimit the taxonomic groupings, as well as earlier attention to harmonizing nomenclature, streamlined the taxonomic scope, there is likelihood that certain cryptic species and/or species complexes yet exist in the data. As we do not address biodiversity responses here, rather phenology related to bioclimatic variability, such issues are expected to have minimal consequences to the results reported.

Fungal ecologies vary substantially by nutritional mode and seasonality of fruiting, so that the fungal data were separated into four groups based on two categories each of nutritional mode (saprotrophic or ectomycorrhizal) and seasonality (spring or autumn fruiting). Main genus-level nutritional mode, when distinguishable, was assigned according to Rinaldi et al. (2008), Tedersoo and Smith (2013), and with additional species-specific information added through expertise. Sensu Kauserud et al. (2010), spring-fruiting fungi were considered to be those whose average fruiting date was before 1 July and autumn-fruiting fungi those with average fruiting date after 1 July. As organisms do not follow calendar years to the start or end of their reproductive seasons, annual seasonal starts were calculated based on the minimum number of fruiting events in relation to a seasonal peak in fruiting. The start of the season for spring-fruiting fungi was set to 1 January and the start of the season for autumn-fruiting fungi was set to 1 March (as many late autumn fruiters can have prolonged fruiting into January and February in oceanic regions of Europe).

Bioclimatic (climate plus primary productivity) variables were obtained from open-source data. Climate data were 
extracted at the 2.5-min resolution from WorldClim for mean annual temperature and precipitation (Hijmans et al. 2005; data available online; http://www.worldclim.org). GIMMS AVHRR Global NDVI-3 g (Normalized Difference Vegetation Index) data with 1/12-degree resolution were extracted from Ecocast (Pinzon and Tucker 2014; data available online; https://ecocast.arc.nasa.gov). The annual averages of monthly mean value concatenated data composites were taken across the temporal extent available for the data that most matched the fungal data set (1982-2010), and averaged across time. NDVI is often used as a measure of initial primary productivity, as it corresponds to the advent of the spring season in northern latitudes (Pettorelli et al. 2005, Nielsen et al. 2012). As these variables are all static, we cannot here address any impact of global change on fungal fruiting phenology.

\section{Statistical analyses}

Data processing and all statistical analyses were conducted in $\mathrm{R}$ version 3.2.2 ( $\mathrm{R}$ Core Team 2015) with the packages corrplot, gamm4, gimms, maps, mgcv, nlme, piecewiseSEM, raster, and rgdal. Bioclimatic data were combined to the fungal recordings based on latitude and longitude coordinates, and analysed with scaled variables and UTM zone 32 geospatial projections (within a zone, the UTM coordinate distances are consistent across northing and easting, unlike latitude/longitude projections). Collinearities were kept as low as possible while retaining geographical and bioclimatic variables (Appendix S2: Fig. S1).

Geographical distributional patterns in fungal phenology were generated through generalized additive mixed modeling with random slope and intercept models (Zuur et al. 2009, Kauserud et al. 2012). These models allow the use of regression analyses without requiring the assumptions of normal distributions or homogeneous variance, and also allow the analyst to incorporate a degree of variability, termed "random," for differing species responses, but while still analyzing overall across species for the fixed, predictor variable(s) effect(s). Data were analysed as spring- or autumnalfruiting fungi and in terms of the seasonal fruiting day start (2.5 percentile), mean, and end (97.5 percentile). Phenology (fruiting day) responses were modeled with spline predictors for the interaction of easting and northing plus altitude. Spline predictors offer a degree of non-linearity that better matches geographical patterns. Offsets and weights by sample size per species and geographical unit (easting and northing combination) helped account for variance among sample units. Species was considered a random effect to account for taxonomic variability in phenology response. The autumnal data were so extensive (over 2 million records) that it could not be processed in its entirety, even in a highperformance computing environment. Thus 100 models (containing 10\% randomized data subsets) were bootstrapped to a mean response across all subsets (Appendix S3: Table S1).

An assemblage of 18 regression models comprised the basis for the path analysis predicting phenology and interdependent relationships between bioclimatic and geographical variability in Europe. The fungal-related regressions of bioclimatic influence on fruiting phenology were considered integral to the analysis (termed models $1-8$ ). Then explanatory regressions of geography on phenology response (models 9-11; more properly accounted for in the previous analyses) as well as bioclimatic response (models 12-18) were considered important within the context of the fungalrelated regressions. In total 18 regressions were run for each of four fungal groupings (Appendices S4-S7: Table S1): paired combinations of season (autumnal- or spring-fruiting) and nutritional mode (ectomycorrhizal or saprotrophic). Linear mixed-effects models accounted for taxonomic variability in response by modeling species as a random factor (Zuur et al. 2009). Unequal sample sizes between species and geographical units were accounted for by weighting by sample sizes. Conditional $R^{2}$ values were used as the main assessment of explained variance, as they account for fixed (bioclimatic and/or geographical) and random (species variability) components (Nakagawa and Schielzeth 2013, Johnson 2014).

To summarize, generalized additive mixed models were utilized to describe geographical and altitudinal patterns of fungal fruiting day. From the available data, we could extrapolate phenology patterns via regressions to the central and northern extents of Europe. Second, path analysis, a statistical technique to model the correlation structure among variables, allowed the testing of direct and indirect relationships between bioclimatic and geographical relationships related to fruiting phenology. For each combination of fruiting season and nutritional mode, we assessed the performance of these path models.

\section{RESULTS \\ Geographical and altitudinal distribution patterns of fruiting phenology}

The geographical and altitudinal patterns in fungal fruiting phenology matched the seasonal onset of spring and autumn in Europe (Fig. 1). For each fungal group (ectomycorrhizal vs. saprotrophic; spring vs. autumn fruiting), across Europe the mean fruiting date varied by approximately $20-25 \mathrm{~d}$; latitude and altitude determined northsouth phenology patterns while longitudinal-related, oceanic effects contributed via non-linearity to the phenology distributions.

For autumnal-fruiting fungi, mean annual fruiting in higher latitudes occurred $5 \mathrm{~d}$ earlier and in lower latitudes $15 \mathrm{~d}$ later, than a mean value longitudinally located across southern Norway to northern Denmark and southern Germany (Fig. 1). There was generally later fruiting in more oceanic environments. Similarly, mean fruiting days at higher altitudes were up to $20 \mathrm{~d}$ earlier than closer to sea level. Trends seen with mean fruiting were similar when the start (2.5th percentile) and the end (97.5th percentile) of the season were considered, but with a couple of exceptions (Appendix S8: Fig. S1). For example, an oceanic effect on longitude had a more pronounced effect on the start of the fruiting season (2.5 percentile) and less of an effect than latitude on the end of the season (97.5th percentile). With greater altitude, fruiting day more sharply accelerated in time in the later season ( 97.5 th percentile) when compared to the earlier season (2.5th percentile). 

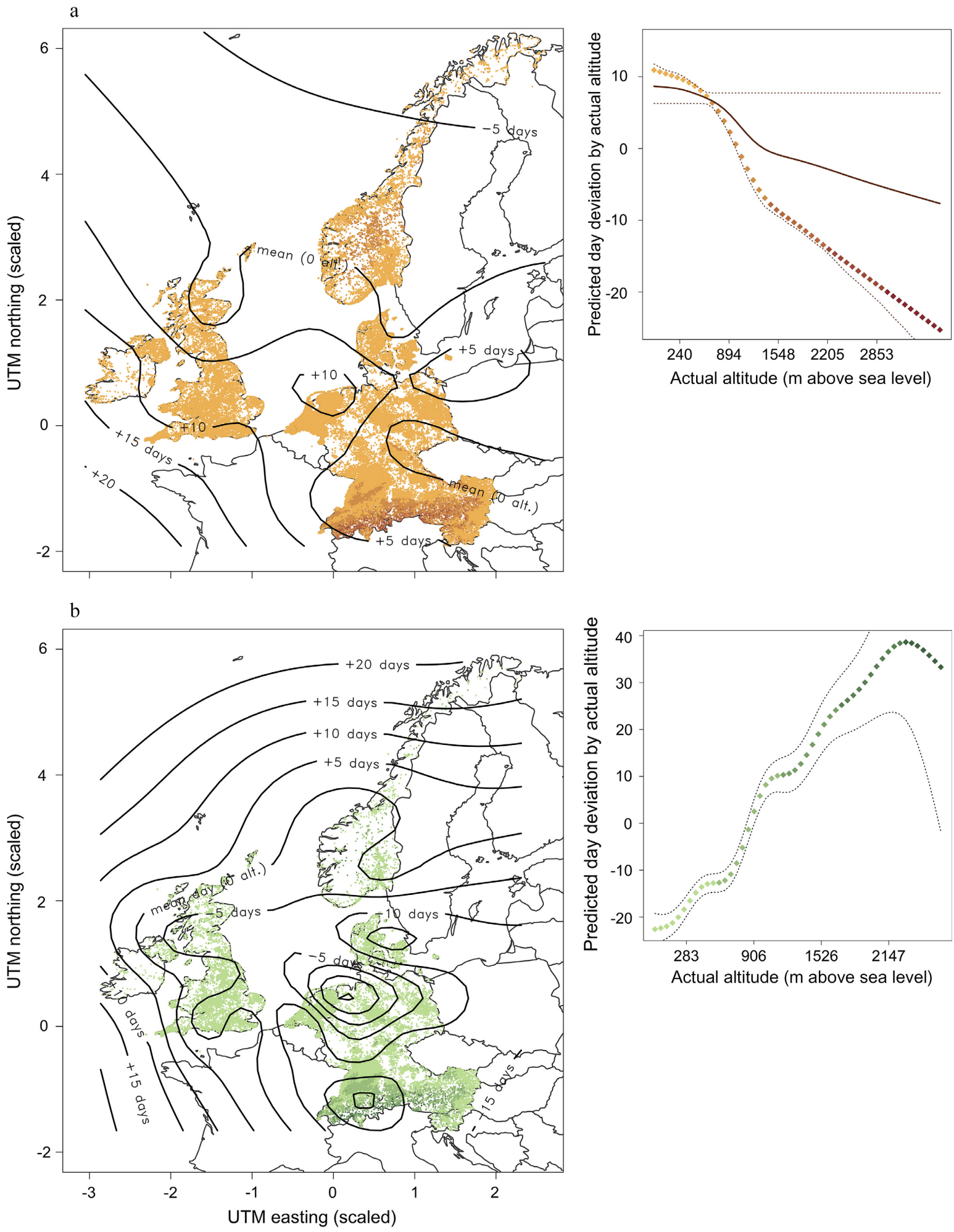

FIG. 1. Spatial distribution and variation in the average fruiting days of fungi throughout Europe for (a) autumnal and (b) spring fruiting taxa. The fruiting day phenology is plotted for mean fruiting. Data points per geographical unit represent the presence of fungal records and are shaded by altitude from low (light) to high (dark). The inset figures illustrate the extent of fruiting day deviation by elevation, in comparison to what is displayed on the map (fruiting at zero altitude). In the inset figures, the model predictions for spring and autumn (one model) are represented by the altitudinal-shaded large dots (corresponding to the $x$-axis values; actual altitude is reported from backcalculating scaled values). As 100 models were bootstrapped for the autumn data, the mean predictions are additionally provided by the solid line. Confidence intervals are represented by the small, dotted lines. Variables were scaled to relativize otherwise widely varying ranges. See Appendix S3: Table S1 for model statistics. 
Patterns of mean fruiting date for spring-fruiting fungi were often opposite to those of the autumn-fruiting fungi (Fig. 1). Increased latitude delayed spring-fruiting (up to 15-20 d) more than it hastened autumn fruiting (5 d). Conversely, with lower latitudes, the earlier fruiting for springfruiting fungi (15 d) was more similar in effect size to the later fruiting by autumnal-fruiting fungi (5-10 d). Altitudinal effects were similar but more pronounced with spring(30 d) than autumn-fruiting (20 d) fungi, and across a lower altitudinal range; elevation changed per fruiting day with approximately 60 - vs. $130-\mathrm{m}$ inclines, respectively. Stronger impacts at higher latitudes and with more sharply increasing altitude caused greater phenology variance to the springthan the autumn-fruiting fungi.

\section{Overall phenological effects of bioclimatic (climate + primary production) variability}

Temperature most strongly and comprehensively affected the average fruiting days of fungi, and was a major component for autumnal-fruiting saprotrophic and ectomycorrhizal, as well as spring-fruiting saprotrophic fruiting. In contrast, the mean fruiting day of spring-fruiting ectomycorrhizal fungi was least affected by temperature (Appendix S4: Table S1), and exhibited greater variability in effects between species (Fig. 2). Mean fruiting day was earlier for spring-fruiting saprotrophic fungi when mean annual temperature was higher (Appendix S5: Table S1), and conversely was delayed for autumnal-fruiting fungi (Appendices S6 and S7: Table S1). The mean fruiting day for autumnal-fruiting fungi was also later both when precipitation and NDVI were higher, though with effects muted compared to those for temperature (Fig. 2). In contrast, precipitation and NDVI had greater effects than temperature for spring-fruiting ectomycorrhizal fungi, and increased levels of the former two caused earlier fruiting (Fig. 2). Precipitation likewise advanced mean fruiting day for spring saprotrophic fungi, while NDVI delayed it.

In terms of model fits (Table 1), the spring-fruiting ectomycorrhizal model explained the greatest amount of variance (conditional $R^{2}=0.61$ ), meaning it best predicted fruiting phenology (compared to other season and nutritional mode combinations). Values of explained variance then decreased from autumnal-fruiting ectomycorrhizal $\left(R^{2}=0.23\right)$, autumnal-fruiting saprotrophic $\left(R^{2}=0.15\right)$, to spring-fruiting saprotrophic $\left(R^{2}=0.10\right)$ fungi. The springfruiting ectomycorrhizal dataset overall generated far higher conditional $R^{2}$ values (the main assessment of explained variance, accounting for fixed (bioclimatic \&/or geographical) and random (species) effects) than the other fungal groups (Table 1), especially compared to the spring-fruiting saprotrophic fungi.

\section{The bioclimatic-geographical phenology network}

Interdependencies (mutually depending on one another) between geography, altitude, climate, and primary productivity varied in relation to fungal fruiting seasonality and nutritional mode (Fig. 3, Table 1). Bioclimatic patterns were best explained within the context of geography and altitude. There was high predictive capacity of the bioclimatic variables by the geographical variables; however, in these

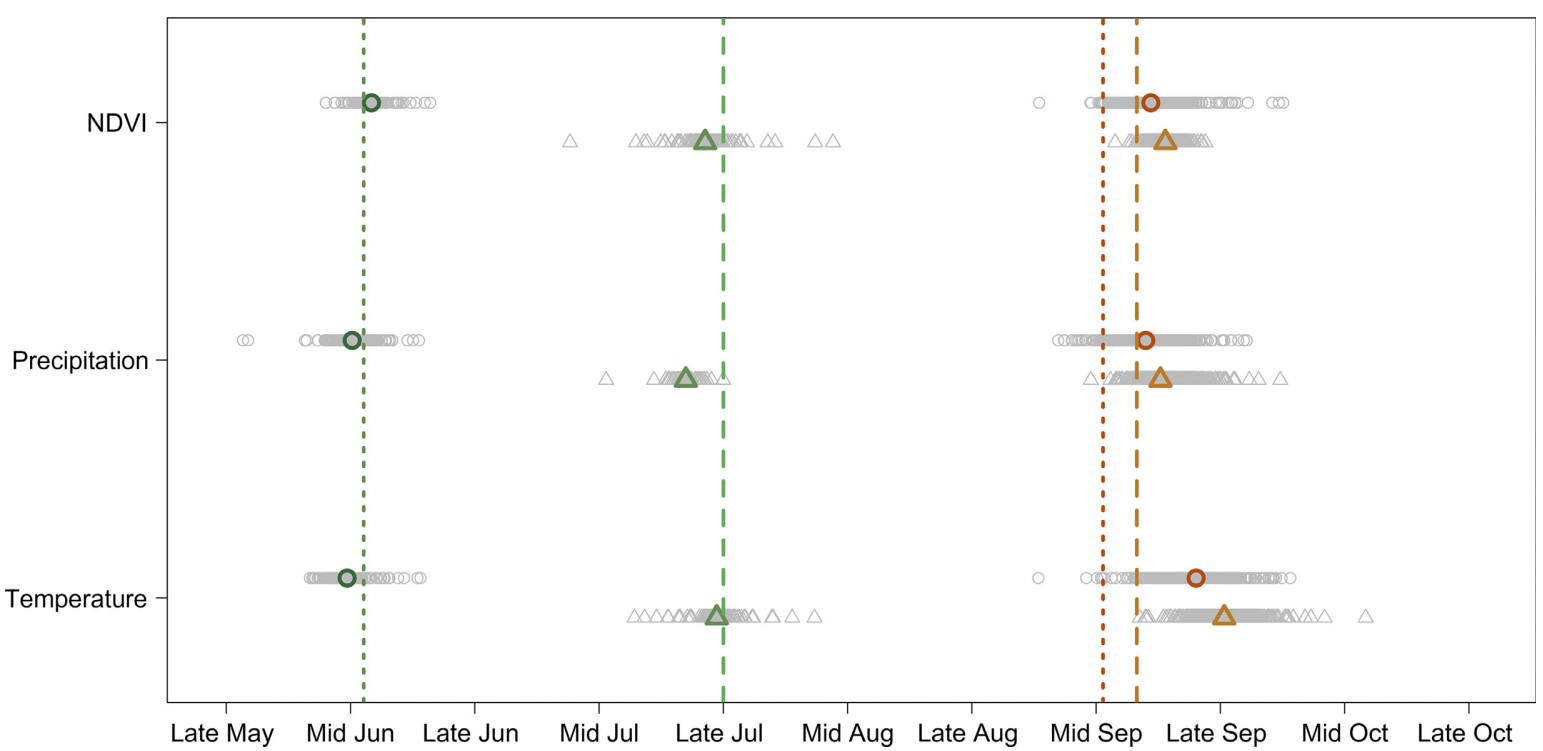

FIG. 2. Bioclimatic (climate plus primary productivity) variable contributions to predicting fruiting phenology by fungal nutritional mode and fruiting season. Regression predictors are on the $y$-axis and fruiting day is on the $x$-axis. Each gray data point is an individual species' slope (contribution) value. The model intercept (dashed lines) can be compared to the mean slope values (larger colored points) for mean annual temperature, summed annual precipitation, and mean normalized difference vegetation index (NDVI). Spring-fruiting fungi are colored green and autumnal-fruiting fungi are colored orange. Saprotrophic slopes are circles and the intercepts short-dashed, while ectomycorrhizal slopes are triangles and the intercepts long-dashed. Note that saprotrophic fungi were analyzed separately from ectomycorrhizal fungi. Intercepts and slopes are reported from random slope and intercept linear mixed models predicting phenology by climate and NDVI (this is the main model, which is referred to as model \#2). A coefficient value greater than the intercept reflects positive correlation while lesser value than the intercept reflects a negative correlation. See Appendices S4 and S5: Table S1 for further statistical information. 


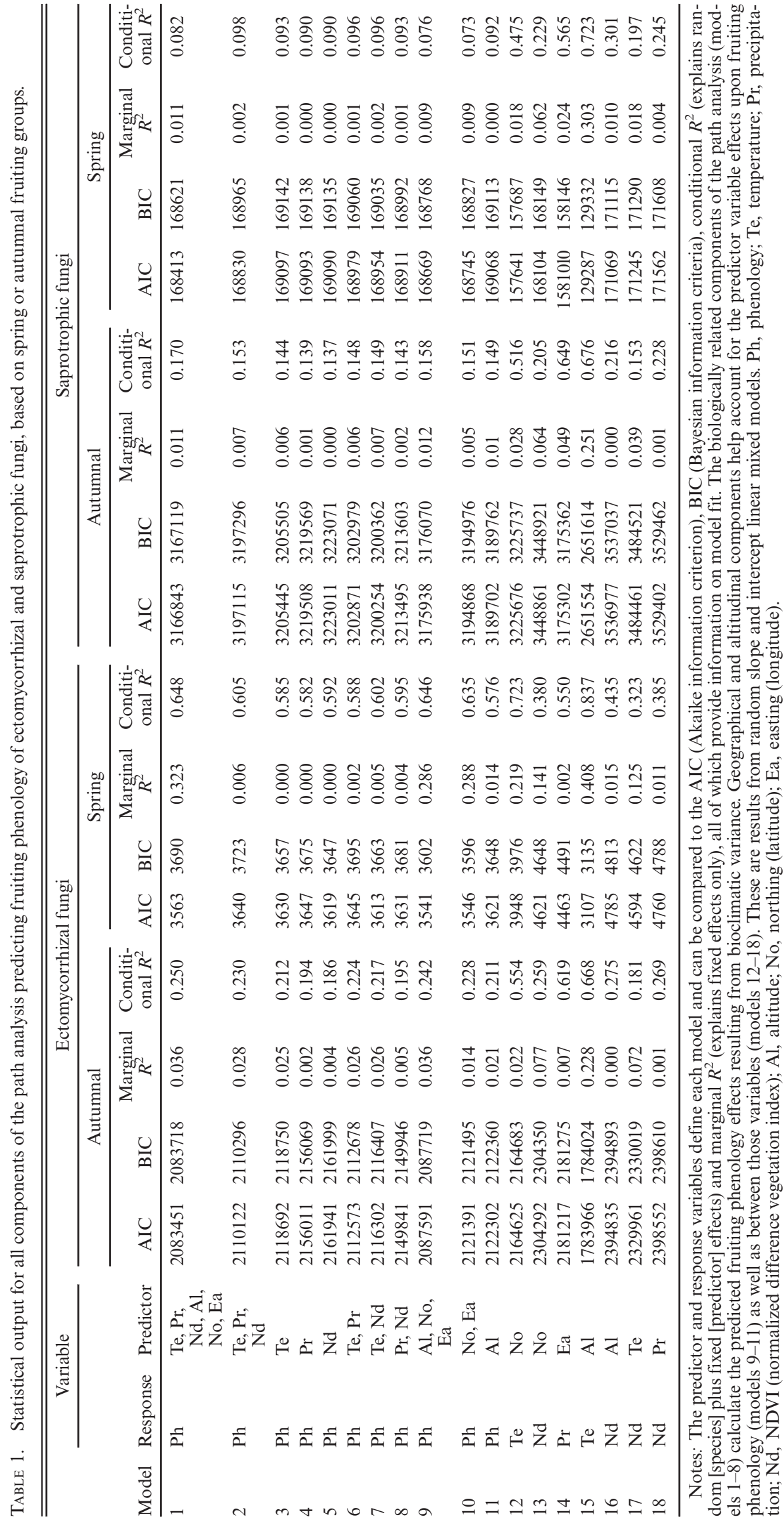


analyses it was the effect of the bioclimatic variables on phenology that was of key interest. In terms of this, the main bioclimatic model (Table 1; what is termed model 2) explained variance in fungal fruiting day, measured by the conditional $R^{2}$, more than any of its individual components did (models 3-8). Model fits were often better when geographical variables were included along with the bioclimatic variables (model 1); this was more due to latitude and longitude (model 10) than to altitude (model 11), though when combined the models were as good as, or better, than the bioclimatic models (models 9 vs. 2). Generally, however, the increase in explaining variance caused by adding geography was not substantially greater than analyzing bioclimatic predictability alone (Table 1).

\section{DisCUSSION}

Fungal biogeographical phenology patterns were characterized through the analysis of 4 million fruit body records distributed across Europe. Fungal phenology reflected known patterns in seasonal onset in non-equatorial regions, and extended established trends (e.g., Kauserud et al. 2012, a

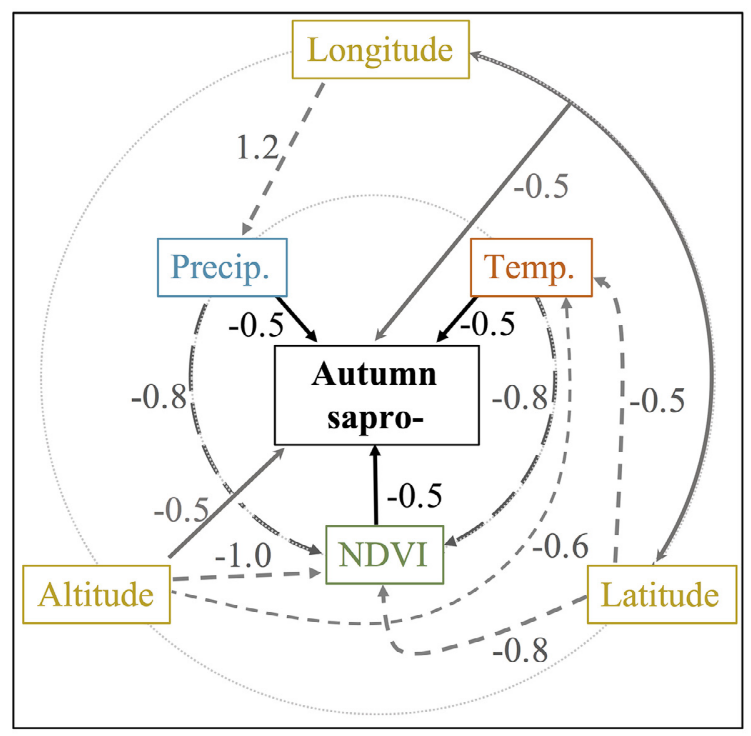

C

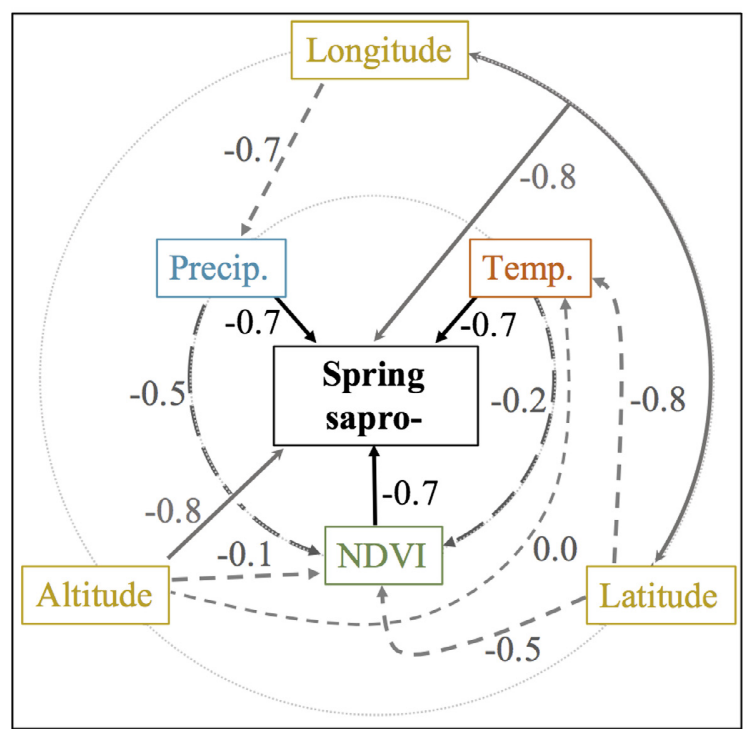

b

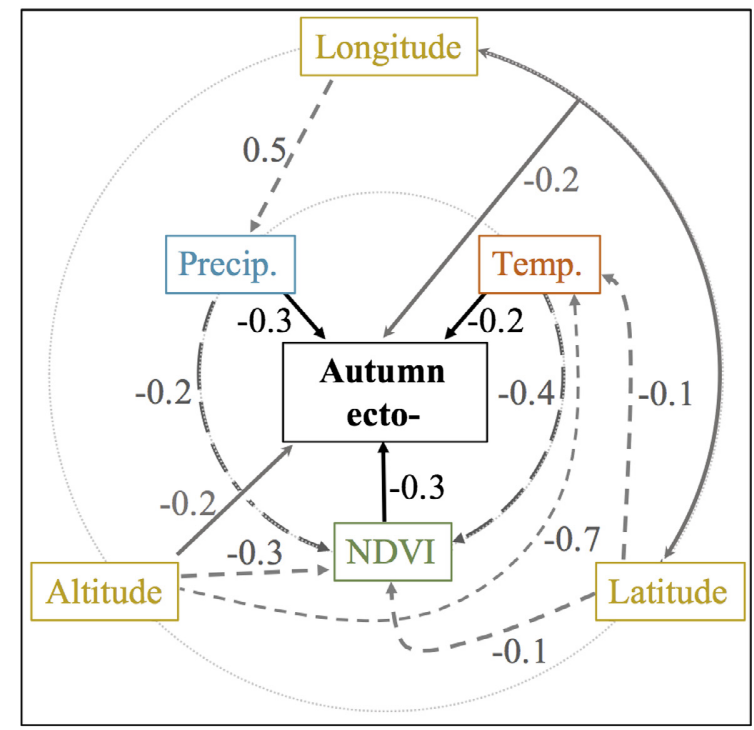

d

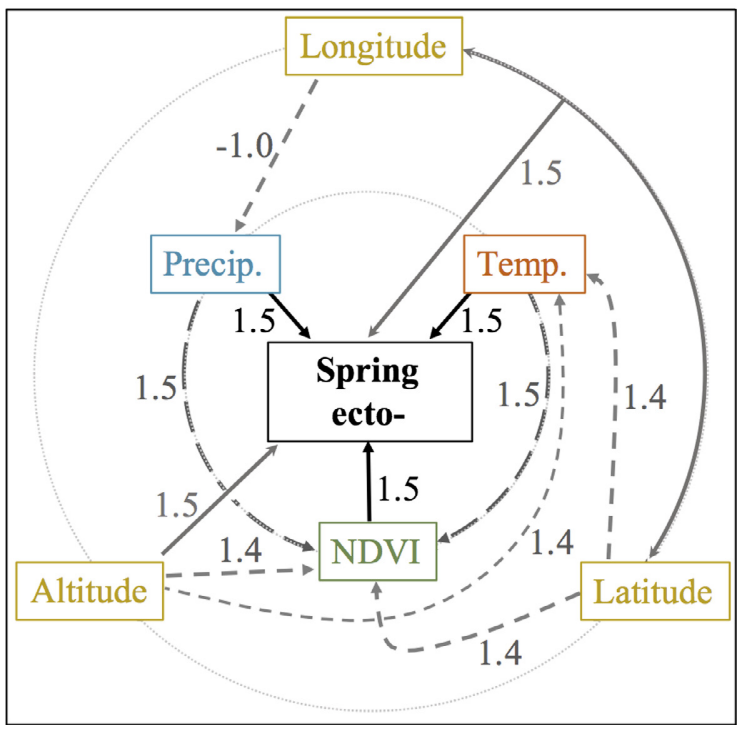

FIG. 3. The path analysis single-effects model results are reported here to most simply describe direct and indirect bioclimatic effects to fungal fruiting phenology. The conditional $R^{2}$ values are relativized by the maximum across all fungal groups for the single-effects models (models 3-5 and 10-18), explaining the amount of variance captured for each to predicting the response variable (pointed to by the arrows). The biologically related components of the path analysis (models 3-5) calculate the predicted fruiting phenology direct effects resulting from bioclimatic variance. Geographical and altitudinal components help account for the predictor variable effects upon fruiting phenology (models 9-11; but see earlier results regarding fruiting phenology and geography), as well as between those variables (models 12-18). (a, b) Autumn season and (c, d) spring season fruiting groups of (a, c) saprotrophic (sap-) and (b, d) ectomycorrhizal (ecto-) nutritional modes are shown. Precip., precipitation; Temp., temperature. 
Andrew et al. 2018). Autumn-fruiting fungi fruited earlier at higher latitudes and altitudes, and in more continental locations, in accord with earlier onset of autumn in those localities (Fig. 1). Spring-fruiting fungi fruited later with higher latitudes and altitudes, and in more oceanic locations, in line with later start of spring in those areas. Stronger impacts at higher latitudes and with more sharply increasing altitude caused greater phenology variance to the spring than the autumn fungi. The extent to which this is a result of seasonal, climatic, photoperiodic, or other variables should be further investigated, as it has parallels to previous findings for plants (Pau et al. 2011, Gill et al. 2015).

In contrast to the geographical effects, direct bioclimatic impacts on fruiting phenology were generally greater for autumn-fruiting than spring-fruiting fungi (Fig. 2, Table 2). Climate especially impacted autumnal-fruiting fungi while NDVI, though less in magnitude, affected spring-fruiting fungi. Related botanical research found early-season (i.e., spring) responses were more often affected by abiotic features while late-season (i.e., autumn) responses were more affected by biotic features (Pau et al. 2011). This matched fungal responses only in spring-fruiting fungi at higher latitudes and altitudes (Fig. 1), demonstrating the need to separate the underlying factors of geography and climate in seasonal responses. Less clear seasonal patterning by fungi compared to plants could be explained by the greater diversity in nutritional modes and ecological roles. Biotic impacts were generally more important for ectomycorrhizal fungi (especially spring-fruiting) while climatic impacts were more important for saprotrophic fungi (especially autumn-fruiting).

While mean annual temperature was positively correlated with earlier mean spring-fruiting day, its effect was even greater with autumnal-fruiting fungal groups. With less of a degree increase, temperature correlated with a greater fruiting delay in autumnal-fruiting fungal groups (Table 2). Temperature impacted saprotrophic fruiting more than ectomycorrhizal fruiting, though with greater variance based on nutritional mode. Precipitation, at the scale used for this study, less dramatically impacted fungal phenology. Precipitation might correlate more to the amount of fruiting than the timing (Büntgen et al. 2015, Heegaard et al. 2016), and is also likely to act on finer temporal scales and spatial resolutions than we present here. From our results, it is suggested that increasing mean annual temperature will impact large-scale fungal fruiting phenology more rapidly than increasing mean total precipitation and with severe interactions depending on geography and altitude.
The link between autumnal fungal fruiting and a shift in the balance of carbon allocation to aboveground plant parts and the belowground root systems is well established (Abramoff and Finzi 2015). The lack of statistical significance of NDVI to autumnal-fruiting ectomycorrhizal fungi was contrary to our expectations, and likely due to the emphasis that NDVI places on the onset of primary production in the spring (Pettorelli et al. 2005, Nielsen et al. 2012). It may not be a proper indicator for carbon dynamics across all seasons, especially for autumnal-based phenology. That the spring-fruiting ectomycorrhizal fungi could fruit earlier with increased primary productivity (NDVI) was likely appropriately captured (Fig. 2). Other measures relating to belowground carbon transfer, such as leaf senescence, belowground carbon and nutrient resorption, or even the climatic indicator of frost days, would likely better explain the onset of autumnal fungal phenology. There is clearly need for further investigations of ectomycorrhizal fruiting comparing measures and indicators of primary production. Overall, fungal fruiting phenology aligned with indications of resource availability (NDVI) more in ectomycorrhizal than saprotrophic taxa.

The magnitude and directions of fruiting day responses (measured by species-specific slopes of the bioclimatic variables) varied across species (Fig. 2). The greatest variability in the response strength and direction occurred with springfruiting species, indicating wide variance in how springfruiting fungi respond to temperature, precipitation and primary productivity. These results, combined with low conditional $R^{2}$ values relative to marginal $R^{2}$ (i.e., explained model variance due to random [species] plus fixed [bioclimatic and geographical] effects vs. fixed effects only; Table 1), suggest that phenology responses related to seasonality and ecology are not fixed across species; general trends exist in fungal phenology, but species do also respond variably. This in itself is not very surprising (Diez et al. 2013), but does indicate a trend across the broadest spatial scale and taxonomic coverage. It also explains why deviations in climatic change responses can occur between localities if the taxonomic representations also differ (Andrew et al. 2016).

\section{Future climate change and phenology shifts}

To consider the likely future shifts in fungal fruiting phenology, the regression results of the main bioclimatic model were relativized and compared to how climate is expected to

TABLE 2. The amount of change in temperature, precipitation or NDVI required to shift fruiting day by one day (earlier or later).

\begin{tabular}{llccc}
\hline \hline & & \multicolumn{2}{c}{ Amount increase in variable (for 1 d earlier or later fruiting) } \\
\cline { 3 - 5 } Season & Nutritional mode & Mean annual temperature & Mean total precipitation & Mean NDVI \\
\hline Spring & Ectomycorrhizal & $2.27^{\circ}$ (earlier) & $62.6 \mathrm{~mm}$ (earlier) & 0.04 units (earlier) \\
Spring & Saprotrophic & $0.73^{\circ}$ (earlier) & $147.5 \mathrm{~mm}$ (earlier) & 0.10 units (later) \\
Autumn & Ectomycorrhizal & $0.16^{\circ}$ (later) & $81.5 \mathrm{~mm}$ (later) & 0.03 units (later) \\
Autumn & Saprotrophic & $0.13^{\circ}$ (later) & $39.7 \mathrm{~mm}$ (later) & 0.02 units (later) \\
\hline
\end{tabular}

Notes: Each of the two seasons and two nutritional modes can be compared. These values were calculated based on the regression slopes of the linear mixed models with randomized slope and intercepts, predicting phenology by climate and NDVI (this is the main model, which is referred to as model 2), calculating from scaled values and contingent on variable ranges. 
change in Europe. First, as mean annual temperature is predicted to continue increasing (Kovats et al. 2014), spring-fruiting fungi can be expected to occur earlier and autumn-fruiting to occur later (Fig. 2). Autumnal-fruiting fungi will likely demonstrate greater phenological responsiveness to temperature fluctuations than spring-fruiting fungi; fruiting by ectomycorrhizal and saprotrophic taxa is predicted (by our regressions) to be delayed by one day with increasing mean annual temperatures of $0.16^{\circ}$ and $0.13^{\circ} \mathrm{C}$, respectively (Table 2). In contrast, mean annual temperatures must increase by $2.27^{\circ}$ and $0.73^{\circ} \mathrm{C}$ for one day advances in springfruiting by ectomycorrhizal and saprotrophic fungi, respectively. Thus, global temperature changes are likely to affect spring-fruiting less than autumnal-fruiting. As the rate of warming is predicted to be greater at higher latitudes (Kovats et al. 2014), and spring fruiting is delayed in northern-most regions (Fig. 1), this might result in large phenological changes, despite relatively low overall responses of springfruiting fungi to temperature increases.

Greater annual precipitation, as with temperature, accelerated the average fruiting day of spring-fruiting fungi and prolonged the day for autumnal-fruiting fungi (Fig. 2). Mean annual precipitation changes throughout Europe are predicted to vary more than temperature, though with general increases in northern Europe, and general decreases in southern Europe (Kovats et al. 2014). We found that saprotrophic autumnal-fruiting fungi were the most responsive to precipitation fluctuations, delaying fruiting by one day per $40 \mathrm{~mm}$ average increase in precipitation (Table 2). Ectomycorrhizal fungi, for the autumnal- and spring-fruiting groups respectively, shifted phenology by one day with 82 and $63 \mathrm{~mm}$ average increases in precipitation. Least affected by precipitation fluctuations were the saprotrophic spring-fruiting fungi, requiring $148 \mathrm{~mm}$ precipitation increase for one day fruiting advance. Thus, given the patchiness of precipitation, we suggest greater heterogeneity in responses by fungal fruiting in the future.

Our use of static bioclimatic variables was due to the availability of data at the time of analyses. If more accurate, temporally changing, bioclimatic covariates had been utilized in the path analyses, we might expect even more precise estimates, but still the same trends as reported here. The extent of climatic variability encompassed across the geographical range of the data far exceeds the change in covariates at given locations across time. Thus, the characterizations of continental-scale fungal fruiting phenology dynamics are likely robust despite global change, though the latter is certainly imperative to incorporate into future studies (inclusive of nitrogen effects), and especially as we continue to so aptly characterize fungal biogeographical patterns at continental scales.

\section{Conclusion}

In summary, we have demonstrated the network of dependencies that relate to fungal biogeographical phenology patterns. Mean annual temperature has a stronger impact on phenology than annual precipitation or primary production, for most fungal groups. Geography and altitude structure phenology in accord with bioclimatic variability. With such a holistic approach, we have affirmed the importance of climate and biogeography for the phenological patterning of fungi. These results demonstrate the significant likelihood that further climatic change, especially temperature, will impact fungal phenology patterns at large spatial scales. Expected ecosystem consequences are many, including effects on food webs that are fruit-body consumption-based, nutrient cycles and the timing of nutrient release, and the potential for disconnect between the responses of both saprotrophic and ectomycorrhizal guilds, as well as asynchrony between fungi and fungal-dependent organisms, including dispersal vectors.

\section{ACKNOWLedgments}

We thank Jeffrey Diez and two anonymous reviewers for constructive manuscript comments. Two funding sources are acknowledged for financial support: The Research Council of Norway, project "Climate change impacts on the fungal ecosystem component (ClimFun)" (14 months), and the Swiss National Science Foundation, project "Linking European Fungal Ecology with Climate Variability - Euro-FC" (7.5 months). Dag Endresen is thanked for help with altitude data extraction and coordinate systems conversion. We thank Anders Nielsen for help with NDVI data. We thank all employees and volunteers associated over the years with the collection and management of the fungal and opensource data. The following organizations are acknowledged for originally providing digitized fungal records data to the meta-database: the Austrian Mycological Society and Wolfgang Dämon; the Swiss national database (www.swissfungi.ch) and Peter Jakob; Deutsche Gesellschaft für Mykologie (German Mycological Society) and Martin Schmidt; The Danish Fungal Atlas project and Tobias Frøslev, Thomas Læssøe, Jens. H. Petersen and Jan Vesterholt; the Netherlands Mycological Society (NMV) and A. van den Berg; the Mycological Herbarium at the Natural History Museum (University of Oslo); the Slovenian Forestry Institute, the Central database of fungi in Slovenia, the Slovenian Mycological Association, and Nikica Ogris; www.fieldmycology.net for support sources of the UK national database.

\section{Literature Cited}

Abramoff, R. Z., and A. C. Finzi. 2015. Are above- and belowground phenology in sync? New Phytologist 205:1054-1061.

Andrew, C., et al. 2016. Climate impacts on fungal community and trait dynamics. Fungal Ecology 22:17-25.

Andrew, C., et al. 2017. Big data integration: Pan-European fungal species observations assembly that addresses contemporary questions in ecology and global change biology. Fungal Biology Reviews 31:88-98.

Andrew, C., C. Heegaard, A. C. Gange, B. Senn-Irlet, S. Egli, P. M. Kirk, U. Büntgen, H. Kauserud, and L. Boddy. 2018. Congruency in fungal phenology patterns across dataset sources and scales. Fungal Ecology 32:9-17.

Austen, E. J., L. Rowe, J. R. Stinchcombe, and J. R. Forrest. 2017. Explaining the apparent paradox of persistent selection for early flowering. New Phytologist 215:929-934.

Boddy, L., U. Büntgen, S. Egli, A. C. Gange, E. Heegaard, P. M. Kirk, A. Mohammad, and H. Kauserud. 2014. Climate variation effects on fungal fruiting. Fungal Ecology 10:20-33.

Bueno, C. G., M. Moora, M. Gerz, J. Davison, M. Öpik, M. Pärtel, A. Helm, A. Ronk, I. Kühn, and M. Zobel. 2017. Plant mycorrhizal status, but not type, shifts with latitude and elevation in Europe. Global Ecology and Biogeography 26:690-699.

Büntgen, U., H. Kauserud, and S. Egli. 2012. Linking climate variability to mushroom productivity and phenology. Frontiers in Ecology and the Environment 10:14-19.

Büntgen, U., S. Egli, J. D. Galván, J. M. Diez, J. Aldea, J. Latorre, and F. Martínez-Peña. 2015. Drought-induced changes in the phenology, productivity and diversity of Spanish fungi. Fungal Ecology 16:6-18. 
Davis, C. C., C. G. Willis, B. Connolly, C. Kelly, and A. M. Ellison 2015. Herbarium records are reliable sources of phenological change driven by climate and provide novel insights into species' phenological cueing mechanisms. American Journal of Botany 102:1599-1609.

Davison, J., et al. 2015. Global assessment of arbuscular mycorrhizal fungus diversity reveals very low endemism. Science 349:970-973.

Diez, J. M., T. Y. James, M. McMunn, and I. Ibáñez. 2013. Predicting species-specific responses of fungi to climatic variation using historical records. Global Change Biology 19:3145-3154.

Gallinat, A. S., R. B. Primack, and D. L. Wagner. 2015. Autumn, the neglected season in climate change research. Trends in Ecology and Evolution 30:169-176.

Gange, A. C., E. G. Gange, T. H. Sparks, and L. Boddy. 2007. Rapid and recent changes in fungal fruiting patterns. Science 316:71.

Gill, A. L., A. S. Gallinat, R. Sanders-DeMott, A. J. Rigden, D. J. Short Gianotti, J. A. Mantooth, and P. H. Templer. 2015 Changes in autumn senescence in northern hemisphere deciduous trees: a meta-analysis of autumn phenology studies. Annals of Botany 116:875-888.

Glassman, S. I., K. G. Peay, J. M. Talbot, D. P. Smith, J. A. Chung, J. W. Taylor, R. Vilgalys, and T. D. Bruns. 2015. A continental view of pine-associated ectomycorrhizal fungal spore banks: a quiescent functional guild with a strong biogeographic pattern. New Phytologist 205:1619-1631.

Halme, P., J. Heilmann-Clausen, T. Rämä, T. Kosonen, and P. Kunttu. 2012. Monitoring fungal biodiversity - towards an integrated approach. Fungal Ecology 5:750-758.

Heegaard, E., et al. 2016. Fine-scale spatiotemporal dynamics of fungal fruiting: prevalence, amplitude, range and continuity. Ecography 40:947-959.

Hijmans, R. J., S. E. Cameron, J. L. Parra, P. G. Jones, and A. Jarvis. 2005. Very high resolution interpolated climate surfaces for global land areas. International Journal of Climatology 25:1965-1978.

Johnson, P. C. D. 2014. Extension of Nakagawa \& Schielzeth's R2GLMM to random slopes models. Methods in Ecology and Evolution 5:944-946.

Kauserud, H., L. C. Stige, J. O. Vik, R. H. Økland, K. Høiland, and N. C. Stenseth. 2008. Mushroom fruiting and climate change. Proceedings of the National Academy of Sciences USA 105:38113814

Kauserud, H., E. Heegaard, M. A. Semenov, L. Boddy, R. Halvorsen, L. C. Stige, T. H. Sparks, A. C. Gange, and N. C. Stenseth. 2010. Climate change and spring-fruiting fungi. Proceedings of the Royal Society B 277:1169-1177.

Kauserud, H., E. Heegaard, R. Halvorsen, L. Boddy, K. Høiland, and N. C. Stenseth. 2011. Mushroom's spore size and time of fruiting are strongly related: Is moisture important? Biology Letters 7:273-276.

Kauserud, H., et al. 2012. Warming-induced shift in European mushroom fruiting phenology. Proceedings of the National Academy of Sciences USA 109:14488-14493.

Kovats, R. S., R. Valentini, L. M. Bouwer, E. Georgopoulou, D. Jacob, E. Martin, M. Rounsevell, and J. F. Soussana. 2014. IPCC AR5 Chapter 23. Pages 1267-1326 in V. R. Barros, C. B. Field, D. J. Dokken, M. D. Mastrandrea, K. J. Mach, T. E. Bilir, M. Chatterjee, K. L. Ebi, Y. O. Estrada, R. C. Genova, B. Girma, E. S
Kissel, A. N. Levy, S. MacCracken, P. R. Mastrandrea, and L. L. White, editors. Climate Change 2014: impacts, adaptation, and vulnerability. Part B: regional aspects. Contribution of Working Group II to the Fifth Assessment Report of the Intergovernmental Panel on Climate Change. Cambridge University Press, Cambridge, UK.

Nakagawa, S., and H. Schielzeth. 2013. A general and simple method for obtaining R2 from generalized linear mixed-effects models. Methods in Ecology and Evolution 4:133-142.

Nielsen, A., N. G. Yoccoz, G. Steinheim, G. O. Storvik, Y. Rekdal, M. Angeloff, N. Pettorelli, Ø. Holand, and A. Mysterud. 2012. Are responses of herbivores to environmental variability spatially consistent in alpine ecosystems? Global Change Biology 18:3050-3062.

Parmesan, C., and M. E. Hanley. 2015. Plants and climate change: complexities and surprises. Annals of Botany 116:849-864.

Pau, S., E. M. Wolkovich, B. I. Cook, T. J. Davies, N. J. Kraft, K. Bolmgren, J. L. Betancourt, and E. E. Cleland. 2011. Predicting phenology by integrating ecology, evolution and climate science. Global Change Biology 17:3633-3643.

Peay, K. G., M. G. Schubert, N. H. Nguyen, and T. D. Bruns. 2012. Measuring ectomycorrhizal fungal dispersal: macroecological patterns driven by microscopic propagules. Molecular Ecology 21:4122-4136.

Pettorelli, N., J. O. Vik, A. Mysterud, J. M. Gaillard, C. J. Tucker, and N. C. Stenseth. 2005. Using the satellite-derived NDVI to assess ecological responses to environmental change. Trends in Ecology and Evolution 20:503-510.

Pinzon, J. E., and C. J. Tucker. 2014. A non-stationary 1981-2012 AVHRR NDVI3 g time series. Remote Sensing 6:6929-6960.

R Core Team. 2015. R version 3.2.2. R Project for Statistical Computing, Vienna, Austria. www.r-project.org

Rinaldi, A. C., O. Comandini, and T. W. Kuyper. 2008. Ectomycorrhizal fungal diversity: separating the wheat from the chaff. Fungal Diversity 33:1-45.

Soudzilovskaia, N. A., J. C. Douma, A. A. Akhmetzhanova, P. M. Bodegom, W. K. Cornwell, E. J. Moens, K. K. Treseder, M. Tibbett, Y. P. Wang, and J. H. Cornelissen. 2015. Global patterns of plant root colonization intensity by mycorrhizal fungi explained by climate and soil chemistry. Global Ecology and Biogeography 24:371-382.

Stenseth, N. C., A. Mysterud, G. Ottersen, J. W. Hurrell, K. S. Chan, and M. Lima. 2002. Ecological effects of climate fluctuations. Science 297:1292-1296.

Swaty, R., H. M. Michael, R. Deckert, and C. A. Gehring. 2016. Mapping the potential mycorrhizal associations of the conterminous United States of America. Fungal Ecology 24:139-147.

Tedersoo, L., and M. E. Smith. 2013. Lineages of ectomycorrhizal fungi revisited: foraging strategies and novel lineages revealed by sequences from belowground. Fungal Biology Reviews 27:83-99.

Tedersoo, L., et al. 2014. Global diversity and geography of soil fungi. Science 346:1256688.

Xie, Y., X. Wang, and J. A. Silander. 2015. Deciduous forest responses to temperature, precipitation, and drought imply complex climate change impacts. Proceedings of the National Academy of Sciences USA 112:13585-13590.

Zuur, A. F., E. N. Ieno, N. J. Walker, A. A. Saveliev, and G. M. Smith. 2009. Mixed effects models and extensions in ecology with R. M. Gail, K. Krickeberg, J. M. Samet, A. Tsiatis, and W. Wong, editors. Spring Science and Business Media, New York, New York, USA.

SUPPORTING INFORMATION

Additional supporting information may be found in the online version of this article at http://onlinelibrary.wiley.com/doi/10.1002/ecy. 2237/suppinfo

\section{Data Availability}

Data associated with this study are available from the Dryad Digital Repository: https://doi.org/10.5061/dryad.150r1jf. 